\title{
Damage control in cardiac surgery: Knowing when to come back another day
}

\author{
Martin Misfeld, MD, PhD, ${ }^{\text {a,b,c,d,e }}$ Paul G. Bannon, MD, PhD, ${ }^{\text {b,c,d,e }}$ Michael A. Borger, MD, PhD, and \\ Tristan D. Yan, MD, $\mathrm{PhD}^{\mathrm{b}, \mathrm{f}, \mathrm{g}}$
}

Video clip is available online.

Damage control surgery (DCS) is a well-established term in general surgery. It is characterized by a staged surgical approach with definite surgical repair following an initial phase of clinical and/or metabolic stabilization. Although DCS has been used in various surgical specialties, this concept has not been well defined in cardiac surgery. The purpose of this review is to define and delineate the various subtypes of DCS, and how these principles are or can be applied in the field of cardiac surgery.

The principles of DCS were initially described by J. H. Pringle, who started to perform intra-abdominal packing for uncontrolled hepatic bleeding, followed by a planned reoperation. ${ }^{1}$ The term "damage control" itself was introduced by M. F. Rotondo in $1993 .{ }^{2} \mathrm{He}$ standardized the surgical concept in patients with complicated exsanguination from severe abdominal trauma. DCS has been translated into various other surgical specialties. Beside trauma surgery, it has been adopted in thoracic surgery, ${ }^{3}$ vascular surgery, ${ }^{4}$ orthopedics, ${ }^{5}$ pediatric surgery, ${ }^{6}$ and other disciplines.

Traditionally, DCS in abdominal trauma includes (1) abbreviated initial laparotomy, (2) intensive care resuscitation, and (3) later definitive repair. Modern principles follow a 5-step approach with additional prehospital and

From the aniversity Department of Cardiac Surgery, Leipzig Heart Center, Leipzig, Germany; 'bepartment of Cardiothoracic Surgery, Royal Prince Alfred Hospital, Sydney, Australia; ${ }^{c}$ RPA Institute of Academic Surgery (IAS), Royal Prince Alfred Hospital, Sydney, Australia; ${ }^{\mathrm{d}}$ The Baird Institute of Applied Heart and Lung Surgical Research, Sydney, Australia; 'Sydney Medical School, The University of Sydney, Sydney, Australia; ${ }^{\mathrm{f}}$ The Collaborative Research Group (CORE), Macquarie University, Sydney, Australia; and ${ }^{\mathrm{g}}$ Sydney Adventist Hospital, University of Sydney, Sydney, Australia.

Received for publication April 12, 2021; accepted for publication Sept 10, 2021; available ahead of print Sept 16, 2021

Address for reprints: Martin Misfeld, MD, PhD, University Department of Cardiac Surgery, Leipzig Heart Center, Struempellstrasse 39, 04289 Leipzig, Germany (E-mail: martinmisfeld@yahoo.com).

JTCVS Techniques 2021;10:362-6

2666-2507

Copyright (C 2021 The Author(s). Published by Elsevier Inc. on behalf of The American Association for Thoracic Surgery. This is an open access article under the CC BY-NC-ND license (http://creativecommons.org/licenses/by-nc-nd/4.0/).

https://doi.org/10.1016/j.xjtc.2021.09.017

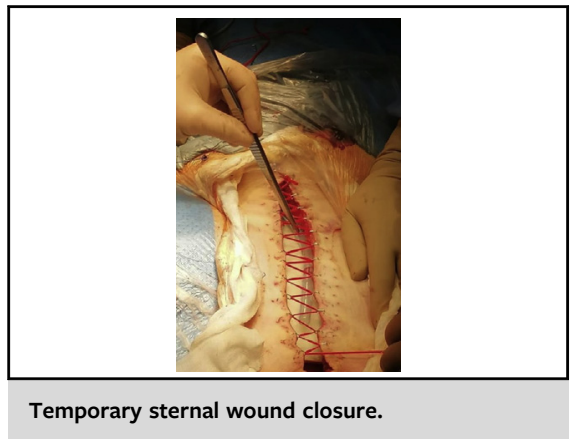

CENTRAL MESSAGE

Damage control in cardiac surgery is defined for the first time. In can be differentiated 2 two types, with categories representing various clinical scenarios.

See Commentaries on pages 367 and 369 .

initial evaluation and final delayed abdominal wall closure following definite repair. DCS is closely related to damage control resuscitation, which includes early blood transfusion, immediate control of ongoing hemorrhage, as well as restoration of physiological circulation addressing hypothermia, coagulopathy, and acidosis. ${ }^{7}$

The principles of DCS cannot be easily adopted to cardiac surgery in its classical trauma form, simply because surgical bleeding from the heart or the great arteries must be controlled immediately. However, there are a variety of scenarios in cardiac surgery whereby the basic concepts of initial damage control, stabilization of the clinical status, and later definite surgical repair can be applied.

In fact, following the first documented suturing of the heart by Capellen and later by Farina, the first successful surgery was performed by Rehn in 1896 . These operations can be viewed as a form of damage control, although definite surgical repair was performed during initial surgery. ${ }^{8}$ This case characterizes the typical scenario of cardiac injuries requiring nondelayed surgical repair. Usually caused by penetrating injuries, the clinical presentation of cardiac trauma can vary from complete hemodynamic stability to cardiopulmonary arrest. ${ }^{9}$ Injuries of the heart are scaled into 6 categories, as per the organ injury scale of the 
American Association for the Surgery of Trauma. ${ }^{10}$ Depending on the severity of the injury, an individualized management approach has to be performed, some requiring delayed surgical intervention and others associated with hemodynamic instability requiring immediate action.

We tried to follow the classical definitions of DCS by introducing 2 basic types. Of these, type $\mathrm{A}$ is the traditional scenario of a trauma with delayed final surgical repair. Both types have various categories and subcategories (bleeding, hemodynamic instability, and infection). By combining these types and categories, the whole spectrum of potential scenarios that can occur in cardiac surgery and require delayed final treatment can be covered. Type A and type B approaches, with various subclassifications along with their applications in cardiac surgery, are described to follow (Video 1).

\section{TYPE A DCS}

Type A DCS is the classic trauma form, with initial physiological stabilization followed by delayed surgical repair. It can be divided into 3 categories, of which category 1 and category 2 can also be subclassified (Table 1). Clinical examples for each category are given in Table 2.

\section{Category 1: Bleeding}

In general, there are 2 principal scenarios of intraoperative bleeding: bleeding after surgical repair (type B, category 1), which is the most common scenario and defined later in the text, and bleeding before surgical repair. The latter one requires further subcategorization with bleeding itself and increased bleeding risk, which are 2 possible scenarios within this context.

Subcategory a: Increased intraoperative bleeding. Intraoperative unexpected bleeding before definite cardiac surgical repair can represent a challenging clinical scenario. Examples of this type of bleeding include damage of surrounding structures during reoperations, or retroperitoneal bleeding caused by peripheral femoral cannulation. The iatrogenic bleeding has to be controlled before definite surgical repair can be performed, with surgery occasionally being interrupted to minimize metabolic derangement and subsequent coagulopathy. The decision to delay definitive repair, however, depends on the original urgency of the clinical indication for surgery.

Redo thoracotomy for reoperative descending and thoracoabdominal aortic repair ${ }^{11}$ is an example of this category. In this series of 60 patients, definite aortic surgical repair was delayed in 4 patients by 12 to 24 hours due to severe intraoperative bleeding. Patients recovered in the intensive care unit between surgical procedures and was associated with good outcomes in all 4 patients. It should be noted that all of the patients in which this approach were applied were elective cases.

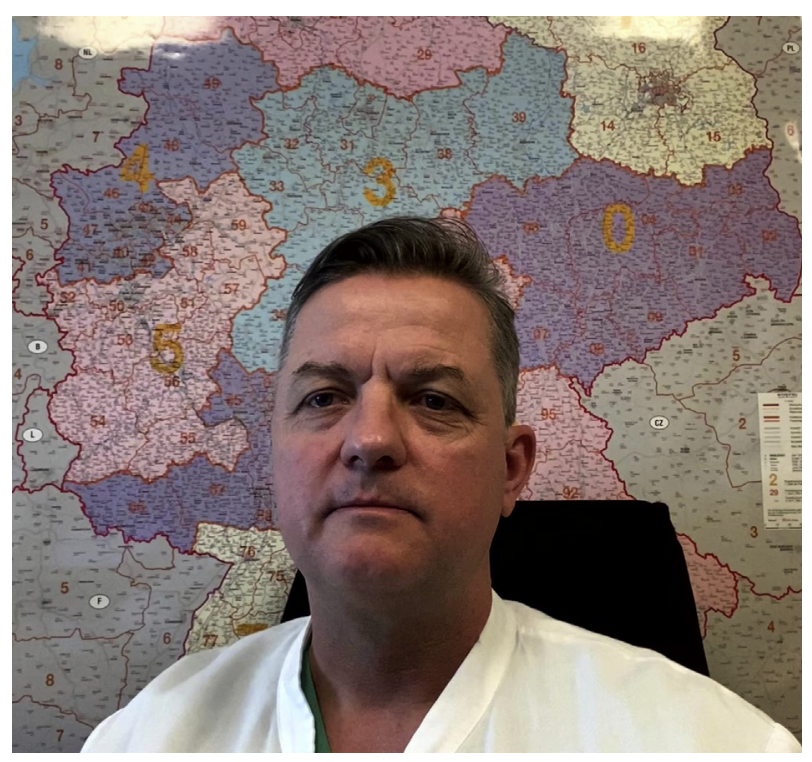

VIDEO 1. First author's comment on the manuscript. Video available at: https://www.jtcvs.org/article/S2666-2507(21)00646-5/fulltext.

Subcategory b: Increased risk of bleeding. A much more common clinical situation is the presence of preoperative antiplatelet or anticoagulation therapy, which require further delay of an urgent cardiac procedure. Dual antithrombotic therapy is commonly employed in patients with severe coronary artery disease (CAD). ${ }^{12}$ It has been shown by $\mathrm{Cao}$ and colleagues that nondiscontinuation of clopidogrel before coronary artery bypass surgery in patients with acute coronary syndrome is associated with increased repeat sternotomy and re-exploration, which itself is associated with a 4.5 -fold increase in perioperative mortality. ${ }^{13}$ Delay of the surgical procedure should therefore be considered, depending on the patient's risk of further ischemic events and the agents used to decrease surgical bleeding complications.

TABLE 1. Classification in cardiac damage control surgery

\begin{tabular}{lll}
\hline Type & \multicolumn{1}{c}{ Category } & \multicolumn{1}{c}{ Subcategory } \\
\hline A & 1: bleeding & $\begin{array}{l}\text { a: increased intraoperative } \\
\text { bleeding } \\
\text { b: increased risk of bleeding } \\
\text { 2: hemodynamic } \\
\text { instability }\end{array}$ \\
& $\begin{array}{l}\text { a: coronary intervention } \\
\text { b: mechanical circulatory support } \\
\text { c: endovascular treatment }\end{array}$ \\
& 3: infection & \\
B & 2: bleeding & \\
& 2: hemodynamic & \\
& instability & \\
& 3: infection & \\
\hline
\end{tabular}

JTCVS Techniques • Volume 10, Number C 
TABLE 2. Classification with examples of cardiac DCS

\begin{tabular}{|c|c|c|c|}
\hline & Complication & Clinical scenarios & Possible decision \\
\hline \multicolumn{4}{|l|}{ Type A } \\
\hline Category 1 a & Intraoperative bleeding & Intraoperative bleeding before cardiac repair & Packing of situs and delayed closure \\
\hline Category $1 \mathrm{~b}$ & Increased bleeding risk & $\begin{array}{l}\text { Preoperative dual antiplatelet therapy or } \\
\text { anticoagulation causing increase bleeding risk }\end{array}$ & Delay of surgery \\
\hline Category 2 a & Coronary intervention & Acute STEMI & PCI of culprit lesion followed by $\mathrm{PCI}$ or $\mathrm{CABG}$ \\
\hline Category $2 \mathrm{~b}$ & $\begin{array}{l}\text { Mechanical circulatory } \\
\text { support }\end{array}$ & $\begin{array}{l}\text { Hemodynamic instability in ischemic or } \\
\text { dilatative cardiomyopathy }\end{array}$ & $\begin{array}{l}\text { ECMO implantation followed by LVAD } \\
\text { implantation }\end{array}$ \\
\hline Category $2 \mathrm{c}$ & Endovascular treatment & Traumatic aortic transection & TEVAR followed by open surgical repair \\
\hline Category 3 & Infection & Cerebral bleeding in IE & $\begin{array}{l}\text { Delay of surgery with stabilization of } \\
\text { neurological status under antimicrobial } \\
\text { treatment followed by cardiac surgery }\end{array}$ \\
\hline \multicolumn{4}{|l|}{ Type B } \\
\hline Category 1 & Bleeding & $\begin{array}{l}\text { Intraoperative severe bleeding after surgical } \\
\text { repair }\end{array}$ & Packing and delayed chest closure \\
\hline Category 2 & Hemodynamic instability & Low-cardiac output following cardiac surgery & Temporary ECMO implantation \\
\hline Category 3 & Infection & $\begin{array}{l}\text { Previous sternal wound infection in patients } \\
\text { requiring urgent cardiac surgery }\end{array}$ & $\begin{array}{l}\text { Vacuum-therapy followed by delayed chest } \\
\text { closure or reconstruction }\end{array}$ \\
\hline
\end{tabular}

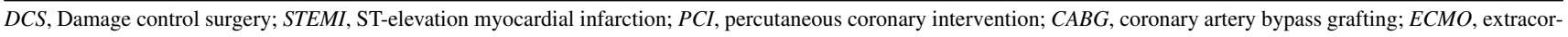
poreal membrane oxygenation; $L V A D$, left ventricular assist device; TEVAR, thoracic endovascular aortic repair; IE, infective valve endocarditis.

\section{Category 2: Hemodynamic Instability}

Subcategory a: Coronary intervention. Revascularization treatment in CAD is complex. In chronic coronary syndromes, it is an important tool in addition to optimal medical therapy. ${ }^{12}$ The best revascularization strategy, either percutaneous coronary intervention (PCI) or coronary artery bypass grafting (CABG), depends on various factors of clinical presentation and investigational findings. Patients with CAD and acute coronary syndromes (myocardial infarction without persistent ST-segment elevation, ${ }^{14}$ as well as patients with acute myocardial infarction and STsegment elevation ${ }^{15}$ ), most frequently undergo initial PCI of the culprit lesion, followed by planned PCI or CABG (ie, final cardiac surgical repair). DCS in this context represents control of the acute myocardial ischemia and physiologic support to limit the end-organ effects of hemodynamic instability, followed by myocardial revascularization for further relief of symptoms and improved prognosis when the patient is stable. Further revascularization should not be delayed, however, if nontreated lesions are thought to be contributing to the hemodynamic instability.

Subcategory b: Short-term mechanical circulatory support. Patients presenting in cardiogenic shock with the necessity of cardiac surgery at a later stage occasionally require more aggressive circulatory support. In this context, initial treatment with short-term mechanical circulatory support can be instituted, either because the hemodynamic instability is life-threatening and final surgical repair is deemed to be too high risk, or the definite decision for cardiac surgical treatment has yet to be made. ${ }^{16}$ Immediate management of deterioration of heart failure with shortterm mechanical circulatory support devices (most frequently, extracorporeal life support) can then be followed by later final cardiac surgery repair including valve surgery, CABG, implantation of long-term ventricular assist devices or, rarely, heart transplantation. Alternatively, the time gained from temporary circulatory support and a thoughtful evaluation of the entire patient condition may result in a palliative approach.

Subcategory c: Endovascular treatment. Acute bleeding associated with hemodynamic instability occasionally requires emergent endovascular treatment. Stent graft interventions in acute, complicated type B dissections, as well as traumatic aortic transection, are part of the therapeutic armamentarium in this context. ${ }^{17}$ The latter pathology is a classic example of initial control of a life-threatening aortic injury, which may require final surgical correction at a later stage. Another example is endovascular treatment of lifethreatening bleeding from an aortoesophageal fistula, which may require delayed definitive surgical repair. Progression of aortic pathologies over time following endovascular therapy (eg, development of an endoleak) should not be seen in the context of DCS as an acute life-threatening situation is not present and treatment of this complications can be done with delay.

\section{Category 3: Infection}

Infective valve endocarditis (IE) is the most common scenario in which definite cardiac surgical repair may be delayed and the principles of DCS applied. Initial antibiotic treatment usually results in surgical repair being performed in the absence of bacteremia. Guidelines on the treatment of the management of IE are useful for guiding surgical treatment in such patients. ${ }^{18}$ Patients presenting with 
hemodynamic instability may require emergent surgery, although the operative risk is high. In multimorbid patients with hemodynamic instability, the initial decision made by the endocarditis team may be a palliative approach. However, a re-evaluation of such patients is occasionally required, when marked clinical improvement occurs. In the clinical scenario of cerebral bleeding caused by embolic events, delayed cardiac surgical repair may also be required in order to minimize the risk of further intracranial hemorrhage. Finally, patients with controlled local IE occasionally require treatment of other infective sources (eg, infected caries, osteomyelitis, infected foreign body, etc) before undergoing final cardiac surgical intervention.

\section{TYPE B}

This type can also be subdivided into 3 categories: bleeding, hemodynamic instability, and infection. In the contrast to type A DCS, this type is characterized by its reverse status. That is, the surgical organ repair has already been performed but cannot be concluded due to one or more of the 3 aforementioned reasons.

\section{Category 1: Bleeding}

Perioperative bleeding in cardiac surgery is not unusual, and the widespread use of modern antiplatelet and anticoagulation therapy has potentially increased the overall risk over the last years. A universal definition of perioperative bleeding in adult cardiac surgery was published by Dyke and colleagues in $2014 .{ }^{19}$ Five classes have been defined with regard to chest tube blood loss within the first 12 hours postoperatively. Delayed sternal closure, defined as leaving the operating room with an open or packed chest, has been recommended in class 3 bleeding (ie, severe bleeding, $1001-2000 \mathrm{~mL}$ in the first 12 hours) but not for massive bleeding (class $4,>2000 \mathrm{~mL}$ in the first 12 hours). DCS within this context may be the most common scenario in cardiac surgery, and the advantages of this strategy have been addressed by various authors. ${ }^{20-22}$ It should be noted that this category cannot be considered completely separate from hemodynamic instability, however, as bleeding complications and hemodynamic instability coexist.

\section{Category 2: Hemodynamic Instability}

Especially in pediatric cardiac surgery, delayed chest closure is often required due to cardiac swelling and associated hemodynamic instability induced by sternal closure. This scenario is also occasionally present in adults, independent of the presence of additional severe bleeding. ${ }^{21,22}$ As hemodynamic instability may require the use of shortterm mechanical support system, which by themselves increase the risk of bleeding, this category is closely related to type B category 1 .

\section{Category 3: Infection}

Deep or superficial sternal wound infection being present before cardiac surgical repair which itself cannot be postponed may also require delayed sternal closure or chest reconstruction at a later stage. Bridging to final chest closure is usually accomplished by vacuum therapy in such patients. Again, this category may also be present with one or both of the previous categories, representing a particularly high-risk clinical scenario.

\section{DCS IN CARDIAC SURGERY}

DCS in cardiac surgery cannot be defined in the classic way as in trauma, orthopedic, or even thoracic surgery. As bleeding complications of the heart or the great vessels often presents as a life-threatening situation, "packing of the heart or aorta" with later surgical repair is usually not an option. However, one of the main characteristics of DCS-uncontrolled hemorrhage requiring physiologic restoration-is present in several different cardiac surgical scenarios. It may therefore be valuable for cardiac surgeons to familiarize themselves with the principles of DCS. In addition, the principles of cardiac DCS can be applied to hemodynamic and infective categories. Two types of DCS can be distinguished in cardiac surgery: initial stabilization followed delayed final repair (type A), and surgical repair followed by subsequent completion (type B).

The principles of DCS are commonly applied in cardiac surgery, without the acknowledgement from cardiac surgeons of the lessons learned from other surgical specialties. Initial stabilization of the clinical setting may significantly improve the chances of overall success in high-risk cardiac surgical patients.

Clinical evaluation of specific aspects of principles of cardiac DCS have be performed. An example for this is the optimal timing of surgery in the presence of IE. ${ }^{18,23}$ Data on other types and categories of the classification of cardiac DCS exist. However, available literature is rare, and, therefore comprehensive analysis of the current literature and categorization with regard to our classification will be a task in the future. It is important to note, that one patient may be categorized with multiple types and categories of cardiac DCS.

Furthermore, individualized patient decision-making, made by a multidisciplinary team in order to address the varieties and complexities of clinical scenarios, may be required to optimally apply the principles of cardiac DCS. This classification with exact definitions of different scenarios of DCS may also help to compare data and research in the future.

\section{Conflict of Interest Statement}

The authors reported no conflicts of interest.

The Journal policy requires editors and reviewers to disclose conflicts of interest and to decline handling or 
reviewing manuscripts for which they may have a conflict of interest. The editors and reviewers of this article have no conflicts of interest.

\section{References}

1. Pringle JH. Notes on the arrest of hepatic hemorrhage due to trauma. Ann Surg. 1908;48:541-9.

2. Rotondo MF, Schwab CW, McGonigal MD, Phillips GR, Fruchtermann TM, Kauder DR, et al. Damage control: an approach for improved survival in exsanguinating penetrating abdominal injury. J Trauma. 1993;35:373-83.

3. Wall MJ Jr, Soltero E. Damage control for thoracic injuries. Surg Clin North Am. 1997;77:863-78.

4. Aucar JA, Hirshberg A. Damage control for vascular injuries. Surg Clin North Am. 1997; 77:853-62.

5. Scalea TM, Boswell SA, Scott JD, Mitchell KA, Kramer ME, Pollak AN. External fixation as a bridge to intramedullary nailing for patients with multiple injuries and with femur fractures: damage control orthopedics. J Trauma. 2000;48:613-21.

6. Stylianos S, Jacir NN, Hoffman MA, Harris BH. Pediatric blunt liver injury and coagulopathy managed with packs and a silo: case report. J Trauma. 1990;30:1409-10.

7. Ball CG. Damage control resuscitation: history, theory and technique. Can J Surg. 2014;57:55-60.

8. Rehn L. Fall von penetrierender Stichverletzung des rechten Ventrikel's. Leipzig: Zentralblatt für Chirurgie; 1896;1048-9.

9. Asensio JA, Soto SN, Forno W, Roldan G, Petrone P, Gambaro E, et al. Penetrating cardiac injuries: a complex challenge. Surg Today. 2001;31:1041-53.

10. Moore EE, Cogbill TH, Malangoni MA, Jurkovich GJ, Shackford SR, Champion HR, et al. Organ injury scaling. Surg Clin North Am. 1995;75:293-303.

11. Etz CD, Zoli S, Kari FA, Mueller CS, Bodian CA, Di Luozzo G, et al. Redo lateral thoracotomy for reoperative descending and thoracoabdominal aortic repair: a consecutive series of 60 patients. Ann Thorac Surg. 2009;88:758-67.

12. Knuuti J, Wijns W, Saraste A, Capodanno D, Barbato E, Funck-Brentano C, et al. 2019 ESC guidelines for the diagnosis and management of chronic coronary syndromes. Eur Heart J. 2020;41:407-77.

13. Cao C, Indraratna P, Ang SC, Manganas C, Park J, Bannon PG, et al. Should clopidogrel be discontinued before coronary artery bypass grafting for patients with acute coronary syndrome? A systematic review and meta-analysis. J Thorac Cardiovasc Surg. 2014;148:3092-8.

14. Roffi M, Patrono C, Collet J-P, Mueller C, Valgimigli M, Andreotti F, et al. 2015 ESC guidelines for the management of acute coronary syndromes in pa- tients presenting without ST-segment elevation. Eur Heart J. 2016;37: 267-315.

15. Ibanez B, James S, Agewall S, Antunes MJ, Bucciarelli-Ducci C, Bueno H, et al. 2017 ESC guidelines for the management of acute myocardial infarction in patients presenting with ST-segment elevation. Eur Heart J. 2018;39: 119-77.

16. Crespo-Leiro MG, Metra M, Lund LH, Milicic D, Constanzo MR, Filippatos G, et al. Advanced heart failure: a position statement of the Heart Failure Association of the European Society of Cardiology. Eur J Heart Fail. 2018;20: $1505-35$.

17. Grabenwöger M, Alfonso F, Bachet J, Bonser R, Czerny M, Eggebrecht H, et al. Thoracic Endovascular Aortic Repair (TEVAR) for the treatment of aortic diseases: a position statement from the European Association for Cardio-Thoracic Surgery (EACTS) and the European Society of Cardiology (ESC), in collaboration with the European Association of Percutaneous Cardiovascular Interventions (EAPCI). Eur J Cardiothorac Surg. 2012;42: $17-24$.

18. Habib G, Lancelotti P, Antunes MJ, Bongiorni MG, Casalta JP, Del Zotti F, et al. 2015 ESC guidelines for the management of infective endocarditis: The task force for the management of Infective Endocarditis of the European Society of Cardiology (ESC). Endorsed by: European Association for Cardio-Thoracic Surgery (EACTS), the European Association of Nuclear Medicine (EANM). Eur Heart J. 2015;36:3075-128.

19. Dyke C, Aronson S, Dietrich W, Hofmann A, Karkouti K, Levi M, et al. Universal definition of perioperative bleeding in adult cardiac surgery. J Thorac Cardiovasc Surg. 2014; 147:1458-63.

20. Bouboulis N, Rivas LF, Dougenis D, Dark JH, Holden MP. Packing the chest: a useful technique for intractable bleeding after open heart surgery. Ann Thorac Surg. 1994;57:856-61.

21. Anderson CA, Filsoulfi F, Aklog L, Farivar RS, Byrne JG, Adams DH. Liberal use of delayed sternal closure for postcardiotomy hemodynamic instability. Ann Thorac Surg. 2002;73:1484-8.

22. Fanning WJ, Vasko JS, Kilman JW. Delayed sternal closure after cardiac surgery. Ann Thorac Surg. 1987;44:169-72.

23. Thuny F, Beurtheret S, Mancici J, Gariboldi V, Casalta JP, Riberi A, et al. The timing of surgery influences mortality and morbidity in adults with severe complicated infective endocarditis: a propensity analysis. Eur Heart J. 2011; 32:2027-33.

Key Words: damage control, cardiac surgery, heart surgery 